\title{
Modelling 3D Topography by Comparing Airborne Lidar Data with Unmanned Aerial System (UAS) Photogrammetry Under Multiple Imaging Conditions
}

\author{
O. G. Ajayi ${ }^{\mathrm{a}, \mathrm{b}^{*}}$ (iD , M. Palmer \\ ${ }^{a}$ Department of Surveying and Geoinformatics, Federal University of Technology, Minna, Nigeria \\ ${ }^{b}$ Faculty of Environment and Technology University of the West of England, Bristol, United Kingdom
}

\section{Article Info:}

Received: 18 October 2019

in revised form: 18 November 2019

Accepted: 15 Dec 2019

Available Online: 30 Dec 2019

\section{Keywords:}

Unmanned Aerial Vehicle; LiDAR

technology; Digital Elevation Model

Terrain Modelling

\section{*Corresponding Author:}

O. G. Ajayi

Department of Surveying and

Geoinformatics, Federal University

of Technology, Minna, Nigeria

Email: ogbajayi@gmail.com,

gbenga.ajayi@futminna.edu.ng

\begin{abstract}
This study presents the effect of image data sources on the topographic modeling of part of the National Trust site located at Weston-Super-Mare, Bristol, United Kingdom, covering an approximate area of 1.82 hectares. The accuracy of the DEM generated from $1 \mathrm{~m}$ resolution and $2 \mathrm{~m}$ resolution LiDAR data together with the accuracy of the DEM generated from the UAV images acquired at different altitudes, are analyzed using the $1 \mathrm{~m}$ LiDAR DEM as reference for the accuracy assessment. Using the NSSDA methodology, the DEMs' horizontal and vertical accuracy generated from each of the four sources was computed. Simultaneously, the paired sample t-test was conducted to ascertain the existence of a statistically significant difference between the means of the $X, Y$, and $Z$ coordinates of the checkpoints. The result obtained shows that with an RMSE of -0.0101499 and horizontal accuracy of $-0.175674686 \mathrm{~m}$, the planimetric coordinates extracted from $2 \mathrm{~m}$ LiDAR DEM were more accurate than the planimetric coordinates extracted from the UAV based DEMs. In contrast, the UAV based DEMs proved to be more accurate than the $2 m$ LiDAR DEM in terms of altimetric coordinates. However, the $D E M$ generated from UAV images acquired at $50 \mathrm{~m}$ altitude gave the most accurate result when compared with the vertical accuracy obtained from the DEM generated from UAV images acquired at $30 \mathrm{~m}$ and $70 \mathrm{~m}$ flight heights. These findings are also consistent with the result of the statistical analysis at a 95\% confidence interval.
\end{abstract}

How to cite (APA 6th Style):

Ajayi, O. G., \& Palmer, M. (2020). Modelling 3D Topography by Comparing Airborne Lidar Data with Unmanned Aerial System (UAS) Photogrammetry Under Multiple Imaging Conditions. Geoplanning: Journal of Geomatics and Planning, 6(2), 122-138. doi: 10.14710/geoplanning.6.2.122-138

\section{INTRODUCTION}

The accuracy of the distances obtained by the electronic distance measurement (EDM) technique is a critical factor to some applications as geodetic network monitoring or geodetic control of structures (Ussisoo, 1969; Brunner, 1984). The accuracy of EDM depends on two factors; the first, known as internal, is related to each instrument's manufacturing characteristics. The second case found the external factors that are more complex since they depend mainly on the environmental conditions of the medium in which the electromagnetic wave propagates (Rüeger, 1990). According to Brunner (1984), Rüeger (1990), Torge \& Müller (2012), and Ogundare \& Adekoya (2015), the principal effect that generates the medium is the variation of the propagation velocity of the wave due to mainly density changes in their composition. This situation directly affects the distance compute and, therefore, their accuracy.

The demands for accurate 3D terrain or elevation models within the last decade has drastically increased due to its multi-faceted applications which cut across many disciplines such as civil and hydrological engineering (Li, Fu, Shen, Huang, \& Zhang 2017), agriculture (Tijskens, Ramon, \& De Baerdemaeker, 2003), urban planning, mapping, geological studies (Yang, Meng, \& Zhang, 2011; Ricchetti, 2001), disaster applications and environmental monitoring and/or analysis (Demirkesen et al., 2007; Tsai et al., 2010), 
security, etc. This surge in demands has propelled the development of different technologies to produce 3D topographic models that accurately depict the terrain configuration of the earth, and more specifically, the area of interest (AOI). The most widely used data structure employed to store and analyze information about topography in a Geographic Information System (GIS) environment is a raster Digital Elevation Model (DEM) (Peralvo \& Maidment, 2004) because of the simplicity of its data structure (Olivera et al., 2002). Digital elevation models can be described as an array of square cells or picture elements (pixels) with each of the pixels having a unique elevation value which defines the height of the point it represents on the earth surface (Peralvo \& Maidment, 2004; Arun, 2013; Rishikeshan, Katiyar, \& Mahesh, 2014). DEMs can also be represented in the form of contour maps and triangulated irregular network (TIN) (Li et al., 2017). Early techniques of the generation of DEMs involved direct interpolation of contour lines produced from topographic surveying using conventional ground surveying techniques or from irregularly spaced threedimensional points collected from field surveys. Apart from the conventional ground surveying techniques' expensive nature, it cannot be deployed in inaccessible and highly risky terrains. Advanced and more technologically sophisticated approaches have seen the introduction of Synthetic Aperture Radar (SAR) interferometry, aerial photogrammetric techniques, laser altimetry, and others (Peralvo \& Maidment, 2004; Ardiansyah \& Yokoyama, 2002; Yue et al., 2015).

Generation of DEMs from SAR consists of two main methods which are the interferometry SAR (InSAR) that uses the phase information from two SAR images of the same scene and the stereo SAR (Huang et al., 2004). The InSAR technique utilizes the phase information of the backscatter signal to measure the distance between the radar sensor and the illuminated target (Chu \& Lindenschmidt, 2017). Each SAR interferogram is generated from precise co-registration of two complex SAR images, cross-multiplying the first SAR image with the complex conjugate of the other (Hanssen, 2001). The processing of Stereo SAR images makes use of three popular models such as (1) the model of the range and doppler equations (Yuan, 2003), (2) the parallax and elevation relation model, which uses the relation between parallax and elevation to calculate elevation difference and the plane coordinates, (3) the equivalent line central projection model based on photogrammetric theory (Huang et al., 2004). Though a relatively fair accuracy of between $1 \mathrm{~m}-10 \mathrm{~m}$ can be obtained from InSAR DEMs (Gelautz et al., 2003; Gruber et al., 2012) especially from single-pass systems like SRTM and TanDEM-X (Chu \& Lindenschmidt, 2017), models that are generated in this way are often compromised by the gaps that occur due to radar shadow and layover. Also, accuracy at this level is generally not good enough for planning purposes that require high-resolution base models. This is especially peculiar with extreme conditions such as high mountain terrains, where there is a high tendency that no information will be extracted within the gapped areas (Hoja, Reinartz, \& Schroeder, 2007). Repeat-pass interferometry (e.g., ERS-ENVISAT, RADARSAT, and ALOS-PALSAR) also suffers from temporal decorrelation that seriously affects the accuracy of the estimated elevations, particularly for dynamic land surfaces, such as vegetation and snow-ice covered areas (Rott, 2009). These major demerits of DEMs generated from SARs made it imperative to investigate other possible alternatives and for this study, LiDAR and UAV photogrammetry are investigated.

Light Detection and Ranging (LiDAR) data have been recognized as a valuable data source for mapping and 3D modeling of the earth surface (Moussa \& El-Sheimy, 2010). LiDAR is a tool that provides both spatial and spectral segmentation, providing high resolution horizontal and vertical spatial point cloud data. It is increasingly being used in a number of applications and disciplines, which have concentrated on the exploit and manipulation of the 3D data it provides (Antonarakis, Richards, \& Brasington, 2008). LiDAR data allows for the generation of a set of crown structural variables based on both the ranges and intensities of individual pulse returns or characterization of the full waveform (Alonzo, Bookhagen, \& Roberts, 2014). The LiDAR sensor rapidly transmits pulses of laser, which travels to the surface, and the signals are returned (reflected) back to the sensor when they make contact with the surface. The return pulses are converted from photons to electrical impulses and collected by a high-speed data recorder. The transmission time intervals are derived and then converted to distance based on positional information obtained from ground/aircraft GPS receivers and the onboard Inertial Measurement Unit (IMU). There are two main types of LiDAR, Terrestrial Laser Scanning (TLS) conducted from the ground, and Airborne Laser Scanning (ALS), which records laser pulses from a scanner mounted on an aircraft. ALS topographic elevation is determined by measuring the round travel time the laser pulse takes from being released from the aircraft, being reflected off a surface, and returning back to the scanner (Olsen, Young, \& Ashford, 2012, Doyle \& Woodroffe, 2018). With the aid 
of direct geo-referencing technique, the laser scanning equipment installed on the aircraft (manned or unmanned) collects a cloud of laser range measurements for calculating the 3D coordinates (xyz) of the survey area. In contrast to the 2D planimetric remote sensing data, the explicit LiDAR data point cloud describes the 3D topographic profile of the earth's surface (Yan, Shaker, \& El-Ashmawy, 2015).

LiDAR has been applied in numerous applications such as the power industry - patrolling electrical power line, electricity distribution, and asset management (Xu et al., 2008; You et al., 2013; Ussyshkin et al., 2011), estimation of herbage removals in pasture quadrats (Radtke, Boland, \& Scaglia, 2010) measurement of tree stem diameter (Wieser et al., 2017), coastal change mapping, forestry, etc. LiDAR can measure surface topography (to within a few centimeters), and it enables difficult-to-access landscapes to be surveyed quickly and accurately (Reddy et al., 2015). However, the costs of LiDAR surveys are prohibitively high (Simpson et al., 2016, Long et al., 2016) and as such, research effort is being invested in the discovery of more costeffective, yet accurate methods and techniques for the extraction 3D topographic modeling.

Recently, attention has shifted to the application of UAV photogrammetry in the generation of DEMs using structure from motion technology due to some advantages such as: (1) a high level of automation of photographic survey; (2) a very low operating cost; (3) a high repeatability of the survey; (4) the possibility to obtain aerial photography with centimetric resolution (Gonçalves \& Henriques, 2015), etc. Unmanned Aerial Vehicle (UAV) platforms provide various types of cost-effective remote sensing data, including true color, multispectral, hyperspectral, microwave, and thermal data, at very high spatial resolutions and at flexible acquisition periods (Bhardwaj et al., 2016; Hardin \& Jensen, 2011; Knoth et al., 2013; Linchant et al., 2015; Shahbazi, Théau, \& Ménard, 2014; Whitehead et al., 2014; Wallace et al., 2012). It is more flexible and controllable than traditional satellite remote sensing in terms of flight height, viewing angles, and forward and side overlap (Anderson \& Gaston, 2013; Candiago et al., 2015; Everaerts, 2008; Turner et al., 2014).

This research seeks to assess and analyze the accuracy of 3D topographic models generated from both airborne LiDAR data and UAV photogrammetry under multiple imaging conditions.

\section{DATA AND METHODS}

\subsection{Study Area}

The study area is located north of Weston-Super-Mare, North Somerset, in the United Kingdom, located $2.91 \mathrm{~km}$ north-west of Wick St Lawrence and $3.5 \mathrm{~km}$ north-east of Kewstoke, UK (Figure 1). It covers about 1.82 hectares and lies approximately between Latitudes 51 o $23^{\prime} 53.09^{\prime \prime} \mathrm{N}$ to $51^{\circ} 23^{\prime} 46.28^{\prime \prime} \mathrm{N}$ and Longitudes $2056^{\prime} 15.11^{\prime \prime} \mathrm{W}$ to $2^{\circ} 56^{\prime} 20.02^{\prime \prime} \mathrm{W}$. The nature of the terrain configuration is quite rugged, which makes it a suitable choice for this research. The site is owned by the National Trust and permissions were obtained from both the National Trust and the former leaseholders (QinetiQ) before conducting the UAV flight missions.

\subsection{Data Acquisition}

DTM LiDAR data of both $1 \mathrm{~m}$ and $2 \mathrm{~m}$ resolution covering the study area were downloaded from the EDINA Digimap services (https://digimap.edina.ac.uk/). EDINA is a world-class center for digital expertise, based at the University of Edinburgh, UK. LiDAR Digimap is a collection of open data from various national and government agencies, including the Environment Agency, Scottish Government, SEPA, Scottish Water and Natural Resources Wales. The data was captured by firing very rapid laser pulses (thousands of times per second) at the ground surface. By examining the laser energy reflected back from the ground, the surface was captured as a dense cloud of 3D points. These points are then converted into highly detailed terrain models of the surface of the earth.

UAV flight missions were conducted over the same study site using a DJI Marvic Pro Quadcopter (https://www.dji.com/mavic/info\#specs) equipped with a SONY camera sensor, the IMX377 of 12 MP resolution, to acquire $2 \mathrm{D}$ overlapping nadir images at different flight heights (see Figure 2a-c). The study area is fenced off and the flight missions were launched outside of the fenced boundary. In essence, the study area was not accessed during the fieldwork and no ground control points (GCPs) were established. This is to examine the accuracy of the models without GCPs and when the area is inaccessible. Three different flight missions were conducted and the images were acquired at $30 \mathrm{~m}, 50 \mathrm{~m}$, and $70 \mathrm{~m}$ flight heights for the first, 
second, and third missions, respectively. Apart from the varied flight heights, other details and specifications were the same for all the flight missions. The sidelap of $65 \%$, front lap of $75 \%$, flight direction of -900 , and maximum flight speed of $15 \mathrm{~m} / \mathrm{s}$ were all specified when the drone deploys app, which was used for the automatic piloting of the drone, was configured at the flight planning stage of each of the flight missions. One hundred seventy-seven overlapping images were acquired at $30 \mathrm{~m}$ altitude, 68 images were acquired at $50 \mathrm{~m}$ altitude, and 44 overlapping images were acquired at $70 \mathrm{~m}$ altitude. Both the LiDAR data and the UAV images were acquired around the same time (February 2018) to ensure that seasonal variation will have minimal effect on the comparative analysis outcome.

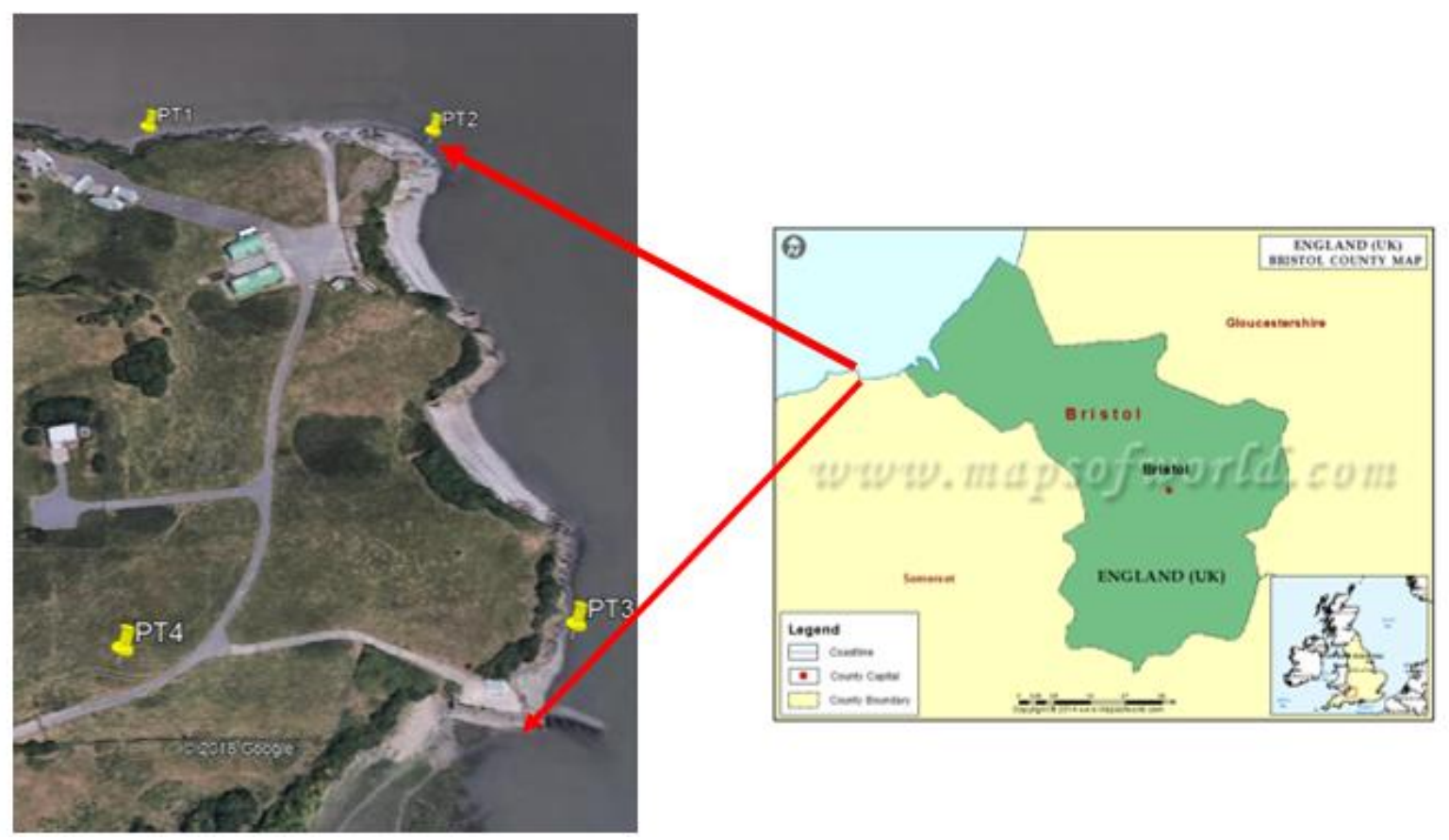

Figure 1. The study area (adapted from www.mapsofworld.com and google earth)

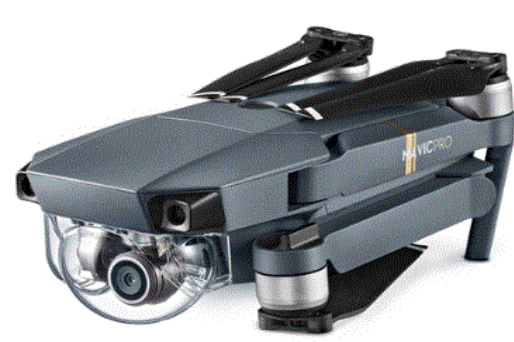

(a)

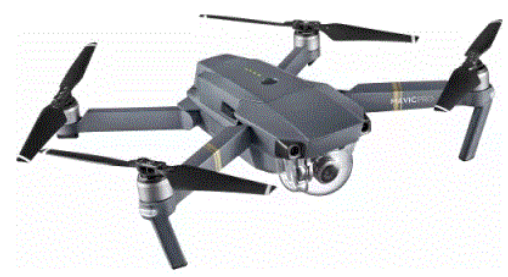

(b)

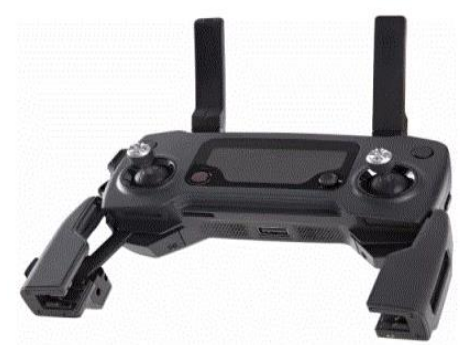

(c)

Figure 2. (a) DJI Marvic Pro UAV in folded form, (b) The UAV with its rotors/propellers fixed, (c) UAV's remote controller (https://www.dji.com/mavic) 


\subsection{Data processing and generation of 3D Topographic Models}

The LiDAR DTM of $1 \mathrm{~m}$ and $2 \mathrm{~m}$ resolution of the study area, which comes in four (4) tiles, were imported into ArcGIS 10.4, where they were mosaicked to get a single LiDAR DTM of the study area at both $1 \mathrm{~m}$ and 2 $\mathrm{m}$ spatial resolutions respectively. The mosaics were then used to generate a Digital Elevation Model (DEM) of the study area and used to extract the XYZ coordinates of each of the cloud points depicting the landscape of the study area. Figures $3 a$ and $b$ present a simplified workflow of the processing stages for generating the DEMs from the LiDAR data.

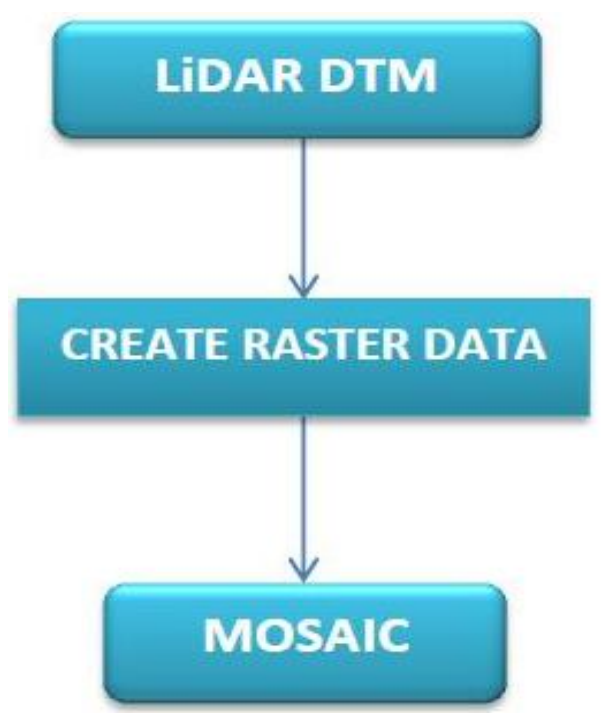

(a)

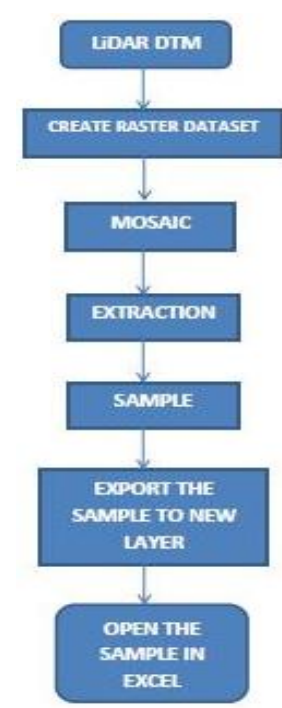

(b)

Figure 3. (a) Process of generating DEM from LiDAR DTM and (b) Process of extracting XYZ data from the LIDAR DTM

All the nadir images acquired during the UAV flight missions were processed using Agisoft photoscan digital photogrammetric software installed on a Laptop computer with 8GB RAM, intel core i5 vPro specifications. The image processing involves relative orientation, interior orientation, absolute orientation, and the generation of 3D models from the 2D acquired image sequences using Structure from Motion (SfM) photogrammetric range imaging technique (Westoby et al., 2012). SfM aims to recover camera parameters, pose estimates, and sparse 3D scene geometry from 2D image sequences (Hartley \& Zisserman, 2003). It is a photogrammetric method for creating $3 \mathrm{D}$ models of a feature or topography from overlapping $2 \mathrm{D}$ photographs taken from many locations and orientations to reconstruct the photographed scene. The steps involved in the generation of the orthomosaics and the DEMs from the 2D nadir images acquired during each of the three (3) flight missions are presented in Figure 4. The orthomosaics are the mosaics of the study area obtained after successfully registering the overlapping image pairs, with their heights and tilt distortions totally removed to ensure geometric correctness. The generated DEMs were finally imported into ArcGIS 10.4 software environment for the representation of the DEM in shades of tone, which depicts the height values of each point on the study area in different colors.

\subsection{Model Precision Assessment}

In order to assess the precision of the generated 3D models, and since the study area was not accessed, which afforded no opportunity for the establishment GCPs, the model generated from the LiDAR data of $1 \mathrm{~m}$ resolution was used as the benchmark for the accuracy evaluation and the models generated from the other four (4) sources were referenced to it. Eight (8) points designated as checkpoints (CPs) were marked on the $1 \mathrm{~m}$ LiDAR generated DTM and their coordinates were extracted. The number of the CPs were restricted to 
eight since a high number of CPs does not significantly affect the altimetric accuracy of the produced 3D models (James et al., 2017), with insignificant effects noticed on the models' accuracy when more than six (6) CPs were used (Oniga, Breaban, \& Statescu, 2018). The coordinates of these CPs were also extracted from the $2 \mathrm{~m}$ LiDAR DTM, and the models produced from the image pairs acquired from the UAV at $30 \mathrm{~m}, 50 \mathrm{~m}$, and $70 \mathrm{~m}$ flight heights.

These coordinates were used to ascertain the accuracy of the generated models using the computed root mean square errors (RMSE), horizontal and vertical accuracy using the methodology from Geospatial Positioning Accuracy, Part 3 of the National Standard for Spatial Data Accuracy (NSSDA), and statistically using paired samples T-test analysis.

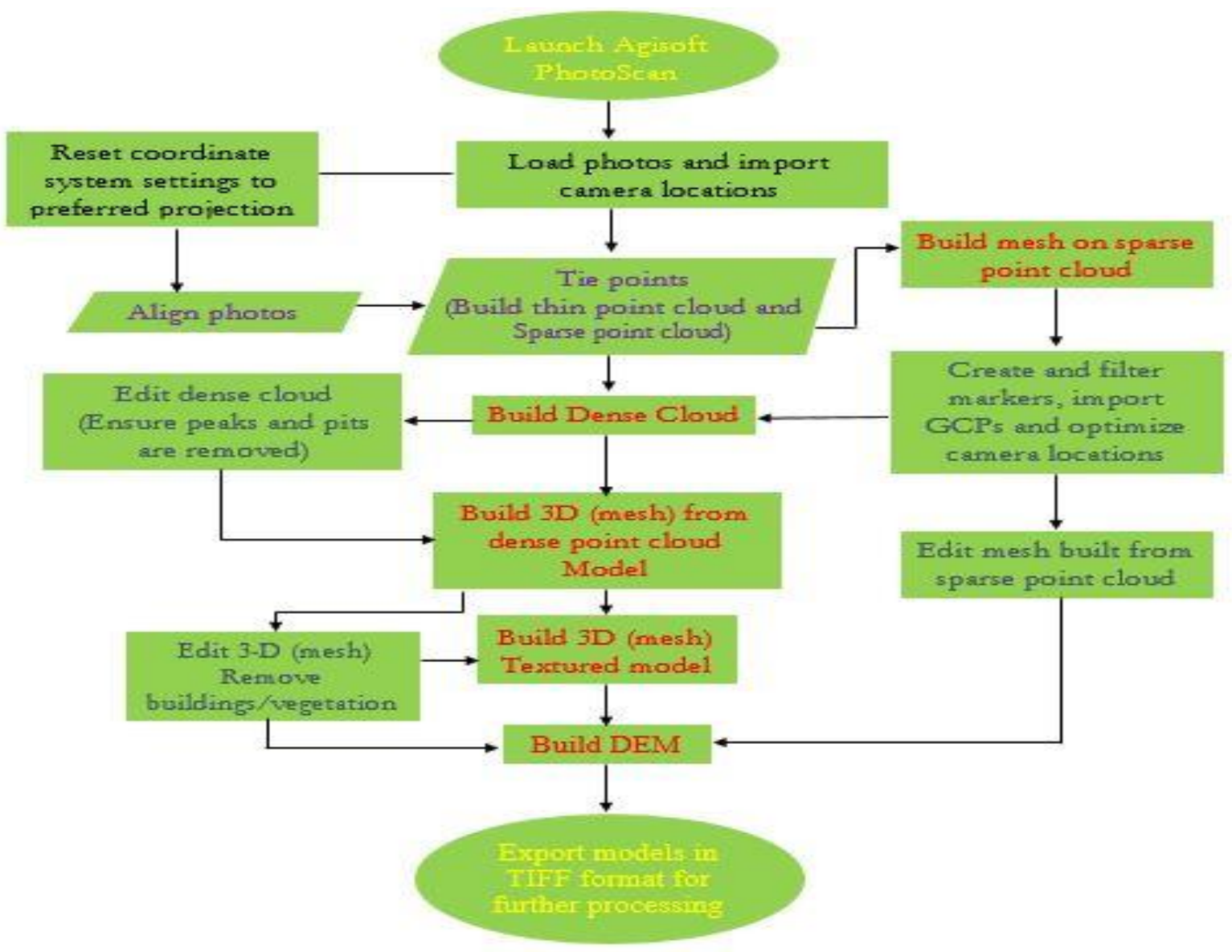

Figure 4. Workflow of the photogrammetric image processing in Agisoft Photoscan (Ajayi et al., 2017)

The horizontal and vertical accuracy was computed by applying a $95 \%$ confidence level to the result obtained using the NSSDA method as presented in equations (1) and (2) respectively (Ajayi et al., 2018):

Horizontal Accuracy $=1.7308 \times$ RMSE $_{\mathrm{r}}$

Vertical Accuracy $=1.96 \times$ RMSE $_{\mathrm{Z}}$

Where RMSE ${ }_{\mathrm{r}}$ and $\mathrm{RMSE}_{\mathrm{Z}}$ depict the root mean square errors of the horizontal and vertical discrepancy respectively computed using equation (3).

$R M S E=\sqrt{\frac{\sum\left(N_{i}-N_{j}\right)^{2}}{n}}$ 
Where $N_{i}$ is the observed values of the coordinates extracted from each of the four 3D models ( $2 \mathrm{~m}$ LiDAR DEM, DEMs generated from images acquired when the UAV was flown at $30 \mathrm{~m}, 50 \mathrm{~m}$, and $70 \mathrm{~m}$ flight heights), $N_{j}$ is the reference values of the coordinates extracted from the $1 \mathrm{~m}$ LiDAR DTM and $n$ is the number of CPs (Ajayi et al., 2017).

Paired samples T-Test is used when testing the statistical difference between two points, between two conditions, two measurements, or between two matched pairs. For this test, the condition for when the population variance is unknown and is unequal was used. The standard deviations $(\sigma)$ computed from the coordinates extracted from each of the models generated from the different data sources were used as the input parameters for the Paired sample T-test, which was conducted using the Statistical Package for Social Sciences (SPSS) V23. The standard deviations were derived from the mathematical manipulations on the deviations of the computed linear distances of each coordinate extracted from the DEMs generated from each of the methods when compared to the reference standard or benchmark ( $1 \mathrm{~m}$ LiDAR DEM accuracy). Equation (4) presents the mathematic expression used for the computation of the standard deviations.

$\sigma=\sqrt{\left\{\frac{\sum v^{2}}{(n-1)}\right.}$

where $\mathrm{v}=$ residual (deviation of each linear distances from the set benchmark) and $n=$ considered number of linear parameters.

For the 2-tailed test, the following hypotheses were postulated and tested for:

i. $H_{0}: \mu_{1}-\mu_{2}=0$ (the difference between the paired population equal to zero)

ii. $H_{1}: \mu_{1}-\mu_{2} \neq 0$ (the difference between the paired population means is not equal to zero).

Where:

$\mu_{1}=$ the mean of the components of the coordinates extracted from the DEM generated from the $1 \mathrm{~m}$ LIDAR data

$\mu_{2}=$ the mean of the components of the coordinates of the other DEMs

The formula for Paired Sample T-test for the difference of two means when the population variance is unknown and unequal is given in equation (5)

$t=\frac{\bar{x}_{\text {diff }}-0}{s_{x}}$

Where:

$s_{x}=\frac{s_{\text {diff }}}{\sqrt{n}}$

And the degree of freedom expressed as $d f=n-1$

$\bar{x}_{\text {diff }}=$ Sample mean of the differences

$n=$ Number of observations (sample size)

$s_{\text {diff }}=$ Sample standard deviation of the differences

$s_{x}=$ Estimated standard error of the mean $\left(\frac{s}{\operatorname{sqrt}(n)}\right)$

The $\mathrm{t}$ value is compared to the critical $\mathrm{t}$ value (table $\mathrm{t}$ value) with $d f=n-1$ from the $\mathrm{t}$ distribution table for a chosen confidence interval. If the obtained $t$ value falls outside the boundary of the confidence interval, it will be concluded that there is a significant difference between the means (and as such, the null hypothesis would be rejected), otherwise, there exists no significant difference between the means and the null hypothesis would be accepted. The test was carried out at a $95 \%$ confidence interval ( $p$-value of 0.05 ). 


\section{RESULTS AND DISCUSSION}

Figures $5 \mathrm{a}$ and $5 \mathrm{~b}$ present the DEM generated from the LiDAR data of $1 \mathrm{~m}$ and $2 \mathrm{~m}$ resolutions, respectively. The orthomosaic and DEM produced from the images acquired when the drone was deployed at $30 \mathrm{~m}$ flight height is presented in Figures $6 \mathrm{a}$ and $6 \mathrm{~b}$, respectively. In comparison, Figures $7 \mathrm{a}$ and $7 \mathrm{~b}$ present the orthomosaic and DEM produced from the flight mission at $50 \mathrm{~m}$, respectively. The orthomosaic and DEM generated from the nadir images acquired by the UAV at $70 \mathrm{~m}$ flight height are presented in Figures $8 \mathrm{a}$ and $8 b$, respectively.

\subsection{Results of model precision assessment for the generated topographic models}

The coordinate differences obtained when the coordinates of the CPs extracted from the $2 \mathrm{~m}$ LiDAR DEM, and the models generated from the UAV images acquired at $30 \mathrm{~m}, 50 \mathrm{~m}$, and $70 \mathrm{~m}$ flight heights were compared with the coordinates of the CPs extracted from the $1 \mathrm{~m}$ LiDAR DEM are shown in Table 1 . The table also presents the summation of the computed discrepancies and the horizontal and vertical accuracy for each of the generated DEMs. The summary of the computed horizontal and vertical accuracies for each of the generated DEMs is presented in Table 2. From Tables 1 and $2, \Delta E(m), \Delta N(m)$, and $\Delta Z(m)$ represent the difference in easting coordinates, northing coordinates, and the height values, respectively.

The paired samples T-test results for each of the DEM obtained from the four sources are presented in Tables 3-6, showing the computed mean values, standard deviation, standard error mean, $t$ - value, significance ( 2 tailed) values, etc. Table 3 presents the t-test result obtained when the means of CP coordinates from the $2 \mathrm{~m}$ LiDAR DEM were compared with the means of the CP coordinates of the reference value (coordinates of the CPs extracted $1 \mathrm{~m}$ LiDAR DEM) while the result obtained when the t-test was conducted using the CP coordinates extracted from the DEM generated from the UAV acquired images at 30 $\mathrm{m}$ flight height was compared with the CP coordinates extracted from $1 \mathrm{~m}$ LiDAR DEM is presented in Table 4. The t-test results obtained when the CP coordinates extracted from the DEMs generated from the UAV images acquired at $50 \mathrm{~m}$ and $70 \mathrm{~m}$ were independently compared with the CP coordinates extracted from the $1 \mathrm{~m}$ LiDAR DEM are presented in Tables 5 and 6 respectively.

Though the visual differences observed in the generated 3D models from each experimented four DEM sources were quite trivial, as shown in Figures 5-8, the computed RMSE and horizontal and vertical accuracy proved considerable differences in the accuracy of each of the models. The horizontal accuracy of the 3D model generated from the $2 \mathrm{~m}$ LiDAR data proved to be better than the horizontal accuracy obtained from the DEM produced from the three UAV flight heights. The model produced from the LiDAR data of $2 \mathrm{~m}$ resolution gave a horizontal accuracy of -0.100255 and -0.072679 along with the $X$ and $Y$ directions, respectively. It was also observed that the planimetric coordinates obtained from the $3 \mathrm{D}$ model produced from the UAV flight mission at $50 \mathrm{~m}$ flight height proved to be more accurate than the coordinates extracted from the 3D models produced from the UAV flight missions conducted at $30 \mathrm{~m}$ and $70 \mathrm{~m}$ altitudes.

Meanwhile, the vertical accuracy obtained from the 3D models produced from the UAV flight missions is each better than the vertical accuracy obtained from the 3D model produced from the LiDAR data of $2 \mathrm{~m}$ resolution. This implies that UAV-based DEM is more accurate in terms of elevation modeling than LiDAR at $2 \mathrm{~m}$ resolution irrespective of the UAV's flight height during image data acquisition. Further observation of the obtained accuracy revealed that the DEM generated from the UAV images acquired at $50 \mathrm{~m}$ flight height is more accurate (with a vertical accuracy of -0.0000735000000011343 ) when compared with the DEM generated from the UAV images acquired at $30 \mathrm{~m}$ and $70 \mathrm{~m}$ flight height. 


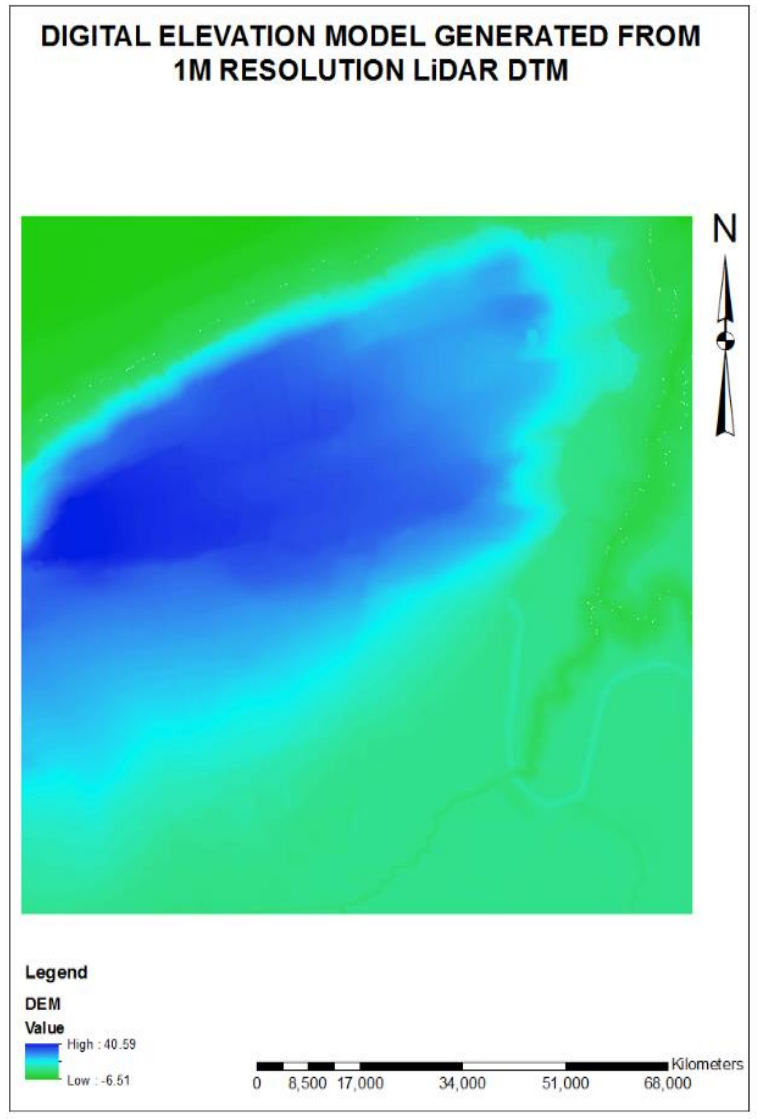

(a)

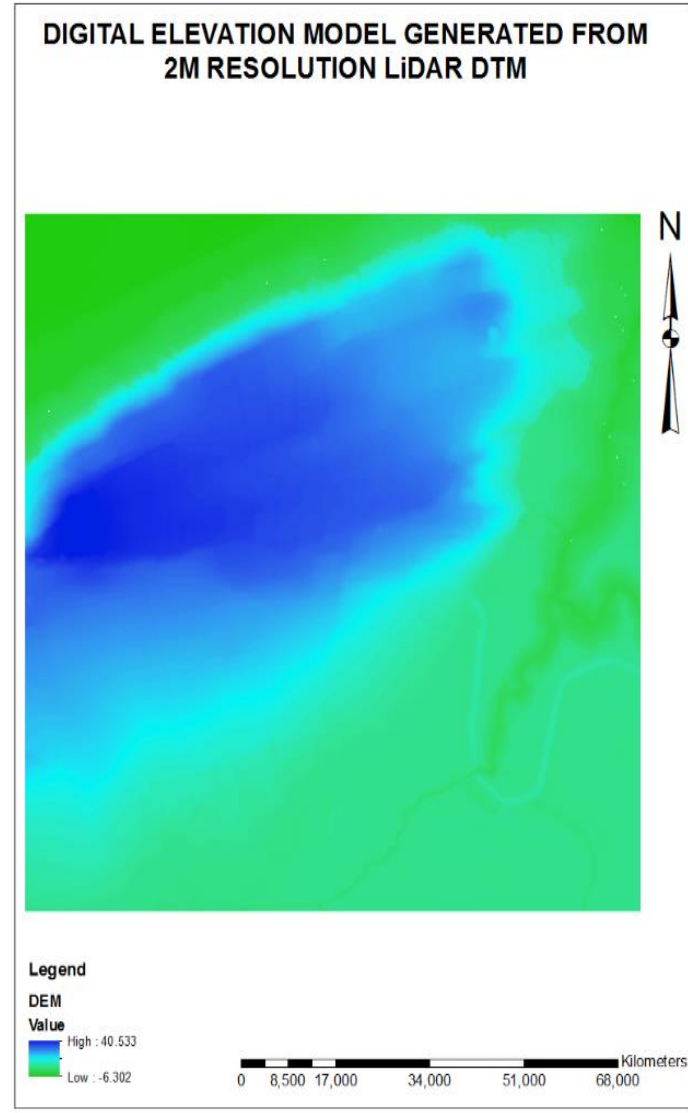

(b)

Figure 5. (a) $1 \mathrm{~m}$ LiDAR DEM and (b) 2 m LiDAR DEM

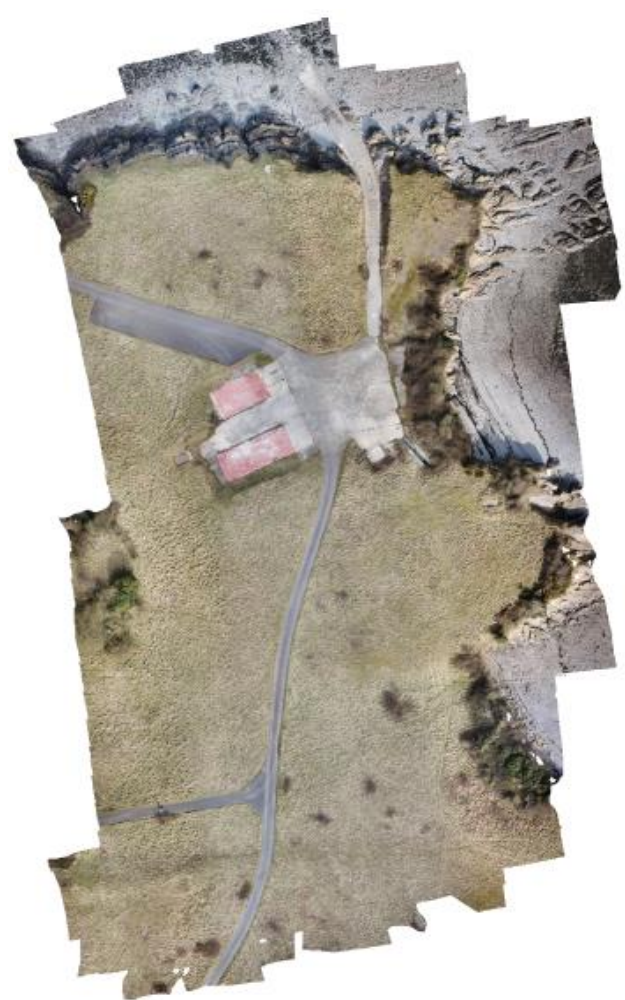

(a)

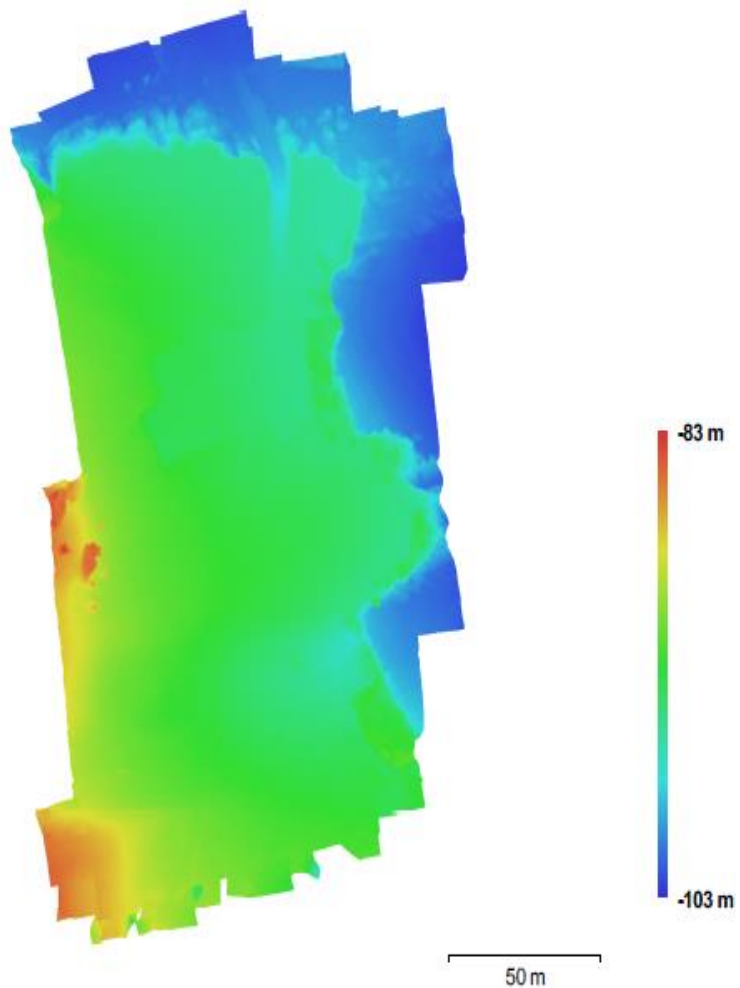

(b)

Figure 6. (a) Orthomosaic at $30 \mathrm{~m}$ altitude and (b) DEM at $30 \mathrm{~m}$ altitude 


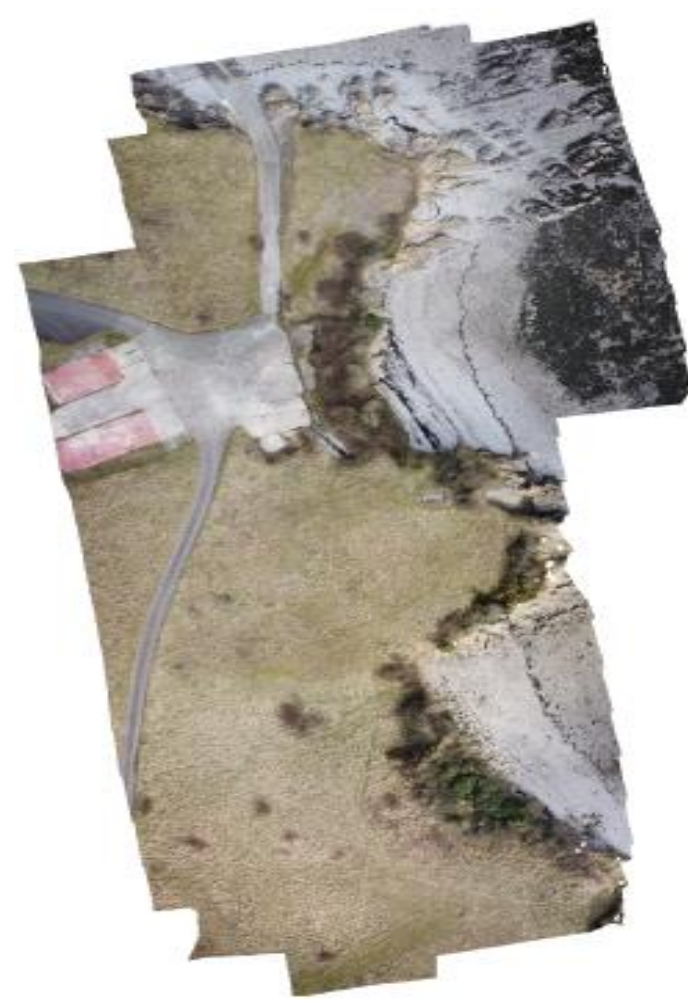

(a)

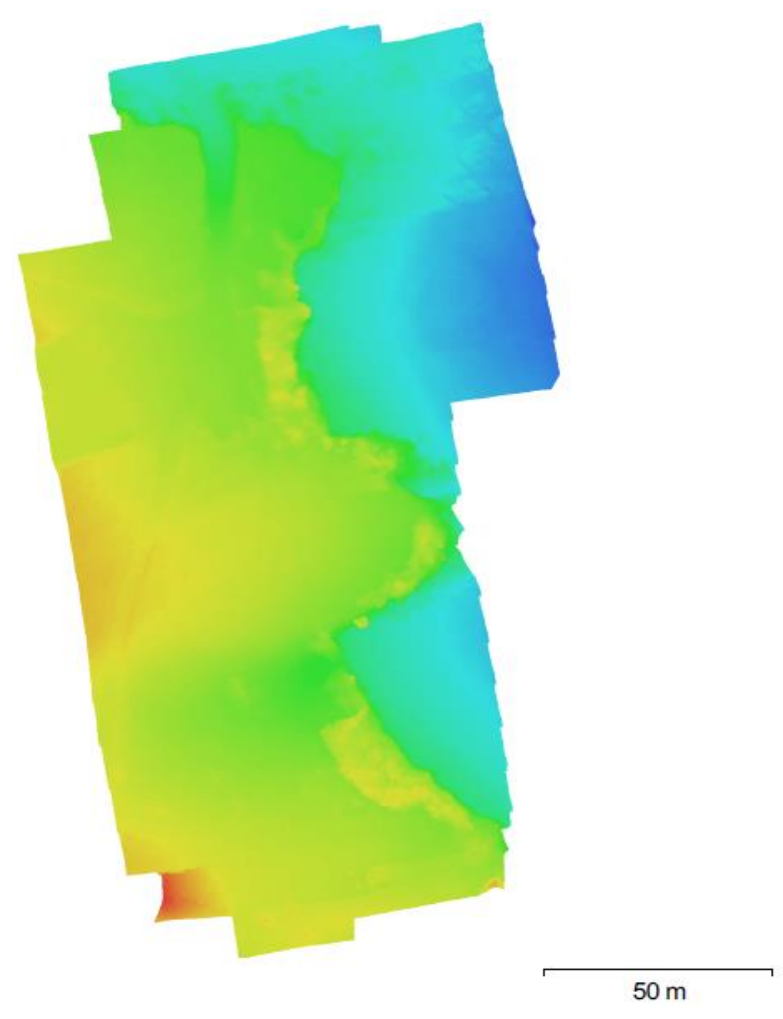

(b)

Figure 7. (a) Orthomosaic at $50 \mathrm{~m}$ altitude and (b) DEM at $50 \mathrm{~m}$ altitude

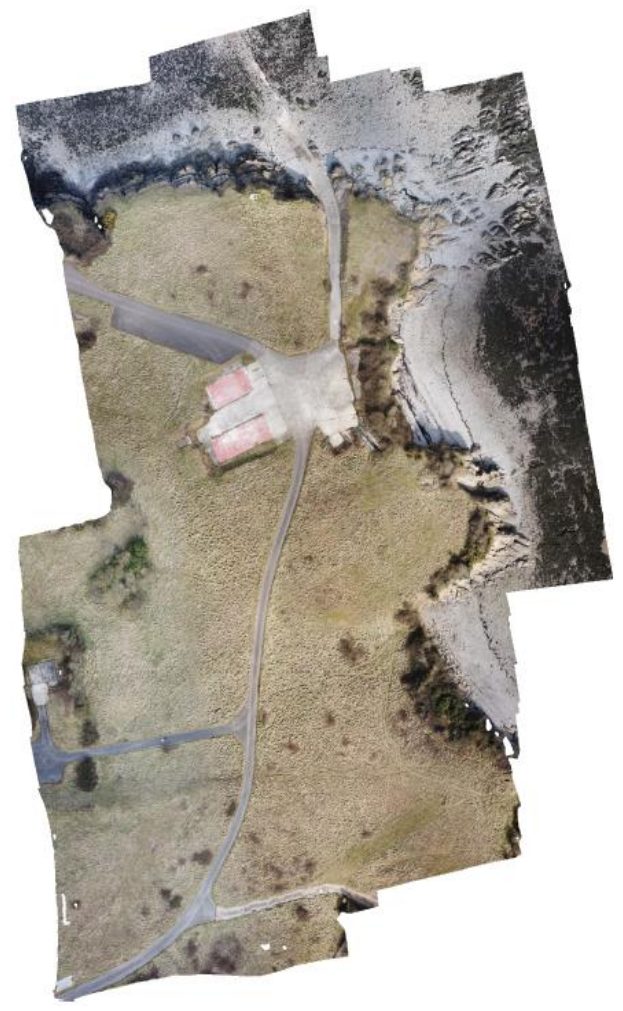

(a)

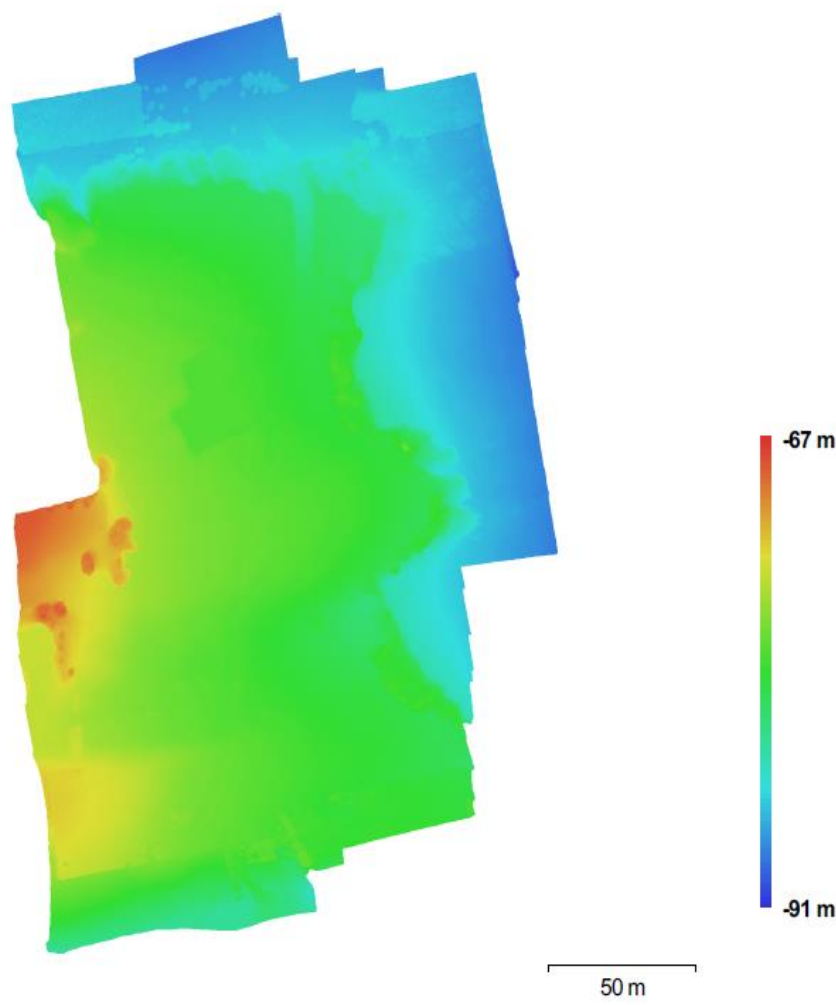

(b)

Figure 8. (a) Orthomosaic at $70 \mathrm{~m}$ altitude and (b) DEM at $70 \mathrm{~m}$ altitude 
Table 1. Computed coordinate differences from the four DEM sources

\begin{tabular}{|c|c|c|c|c|c|c|c|c|c|c|c|c|}
\hline \multirow{2}{*}{ CP ID } & \multicolumn{3}{|c|}{ LIDAR DTM+2M POINTS } & \multicolumn{3}{|c|}{$30 \mathrm{M}$} & \multicolumn{3}{|c|}{$50 \mathrm{M}$} & \multicolumn{3}{|c|}{$70 \mathrm{M}$} \\
\hline & $\Delta \mathrm{X}(\mathrm{m})$ & $\Delta \mathrm{Y}(\mathrm{m})$ & $\Delta \mathrm{Z}(\mathrm{m})$ & $\Delta \mathrm{X}(\mathrm{m})$ & $\Delta \mathrm{Y}(\mathrm{m})$ & $\Delta \mathrm{Z}(\mathrm{m})$ & $\Delta \mathrm{X}(\mathrm{m})$ & $\Delta \mathrm{Y}(\mathrm{m})$ & $\Delta \mathrm{Z}(\mathrm{m})$ & $\Delta \mathrm{X}(\mathrm{m})$ & $\Delta \mathrm{Y}(\mathrm{m})$ & $\Delta \mathrm{Z}(\mathrm{m})$ \\
\hline CP1 & -0.4727 & 1.54992 & 0.32 & 0.75252 & -2.60328 & -1.3439 & -0.9675 & -2.8774 & -0.4751 & -0.9675 & -2.8774 & -1.0862 \\
\hline $\mathrm{CP} 2$ & -0.6155 & 0.36019 & 0.138 & 2.6085 & -2.86502 & -0.9909 & -0.8692 & -2.9884 & 0.5741 & 0.43987 & -3.5416 & -0.7467 \\
\hline CP3 & 0.0462 & -0.374 & -0.055 & -0.11558 & 1.55582 & 0.2552 & -0.0043 & 2.65787 & 1.3949 & 0.12459 & 2.53592 & 0.0095 \\
\hline CP4 & -0.7628 & -0.0884 & 1.383 & -0.08862 & 0.589759 & 0.3357 & -0.2719 & 1.69419 & 3.1644 & 0.25546 & 1.93511 & 0.0025 \\
\hline CP5 & 0.15328 & -0.5104 & -0.36 & 1.59009 & 0.353003 & 1.2442 & 0.66794 & 1.07196 & -2.7173 & 0.95027 & 1.75189 & 1.2125 \\
\hline CP6 & 1.15781 & -1.0314 & -2.782 & 2.75028 & -2.85233 & 0.5708 & -0.8289 & -2.6291 & -4.2152 & -0.9313 & -2.7621 & 0.6371 \\
\hline CP7 & -0.0022 & 0.53012 & -0.453 & 1.66644 & -2.59356 & 1.0878 & 7.48331 & 2.60879 & 4.0263 & -1.13 & -3.1327 & 1.5603 \\
\hline CP8 & 0.02518 & -0.7773 & -0.333 & -0.49749 & 1.267905 & -1.1593 & -0.2499 & 1.64342 & -1.7524 & -0.015 & 1.58136 & -1.5894 \\
\hline SUM & -0.47074 & -0.34126 & -2.142 & 8.66615 & -7.1477 & -0.0004 & 4.95945 & 1.18138 & -0.0003 & -1.27361 & -4.50957 & -0.0004 \\
\hline RMSE & -0.05884 & -0.04266 & -0.26775 & 1.08327 & -0.89346 & $-5 \mathrm{E}-05$ & 0.61993 & 0.14767 & $-3.75 E-05$ & -0.1592 & -0.5637 & $-5 E-05$ \\
\hline Accuracy & -0.10026 & -0.07268 & -0.52479 & 1.84567 & -1.52228 & $-9.8 \mathrm{E}-05$ & 1.05624 & 0.2516 & $-7.35 \mathrm{E}-05$ & -0.27125 & -0.96043 & $-9.8 \mathrm{E}-05$ \\
\hline
\end{tabular}

Table 2. The accuracy obtained from each of the four DEM sources

\begin{tabular}{crr}
\hline DEM Source & Horizontal Accuracy & Vertical Accuracy \\
\hline 2m LiDAR DTM & -0.175674686 & -0.5247900000000000000 \\
\hline UAV DEM @ 30m Altitude & 0.328515143 & -0.0000980000000002068 \\
\hline UAV DEM @ 50m Altitude & 1.328569003 & -0.0000735000000011343 \\
\hline UAV DEM @ 70m Altitude & -1.251190993 & -0.0000979999999997716 \\
\hline
\end{tabular}

Table 3. Paired sample t-Test of LIDAR DATA $1 \mathrm{~m}$ resolution and LIDAR DATA $2 \mathrm{~m}$ resolution

\begin{tabular}{|c|c|c|c|c|c|c|c|c|c|}
\hline & & \multicolumn{5}{|c|}{ Paired Differences } & \multirow{3}{*}{$\mathrm{T}$} & \multirow{3}{*}{$\mathrm{df}$} & \multirow{3}{*}{$\begin{array}{r}\text { Sig. } \\
(2- \\
\text { tailed) }\end{array}$} \\
\hline & & \multirow{2}{*}{ Mean } & \multirow{2}{*}{$\begin{array}{r}\text { Std. } \\
\text { Deviation }\end{array}$} & \multirow{2}{*}{$\begin{array}{r}\text { Std. Error } \\
\text { Mean }\end{array}$} & \multicolumn{2}{|c|}{$\begin{array}{r}95 \% \text { Confidence Interval of } \\
\text { the Difference }\end{array}$} & & & \\
\hline & & & & & Lower & Upper & & & \\
\hline Pair 1 & $\begin{array}{l}\text { Lidar Data-1mX } \\
\text { (mE) - LiDAR } \\
\text { Data-2mX (mE) }\end{array}$ & .059000000 & .600550224 & .212326568 & -.443072552 & .561072552 & .278 & 7 & .789 \\
\hline Pair 2 & $\begin{array}{l}\text { Lidar Data-1mY } \\
(\mathrm{mN}) \text { - LiDAR } \\
\text { Data-2mY }(\mathrm{mN})\end{array}$ & .042625000 & .834517643 & .295046542 & -.655049209 & .740299209 & .144 & 7 & .889 \\
\hline Pair 3 & $\begin{array}{l}\text { LiDAR Data-1mZ } \\
\text { (Heights- } \mathrm{m} \text { ) - } \\
\text { LiDAR Data-2mz } \\
\text { (Heights- m) }\end{array}$ & .267750000 & 1.174056430 & .415091631 & -.713785738 & 1.249285738 & .645 & 7 & .539 \\
\hline
\end{tabular}


Table 4. Paired sample t-Test of LiDAR DATA $1 \mathrm{~m}$ resolution and DEM generated from UAV images acquired at $30 \mathrm{~m}$ flight height

\begin{tabular}{|c|c|c|c|c|c|c|c|c|c|}
\hline & & \multicolumn{5}{|c|}{ Paired Differences } & \multirow{3}{*}{$\mathrm{T}$} & \multirow{3}{*}{ Df } & \multirow{3}{*}{$\begin{array}{l}\text { Sig. (2- } \\
\text { tailed) }\end{array}$} \\
\hline & & \multirow[t]{2}{*}{ Mean } & \multirow{2}{*}{$\begin{array}{r}\text { Std. } \\
\text { Deviation }\end{array}$} & \multirow{2}{*}{$\begin{array}{r}\text { Std. Error } \\
\text { Mean }\end{array}$} & \multicolumn{2}{|c|}{$\begin{array}{r}\text { 95\% Confidence Interval of the } \\
\text { Difference }\end{array}$} & & & \\
\hline & & & & & Lower & Upper & & & \\
\hline $\begin{array}{l}\text { Pair } \\
1\end{array}$ & $\begin{array}{l}\text { Lidar Data- } \\
1 \mathrm{mX}(\mathrm{mE})- \\
\text { UAV-30M x }\end{array}$ & -1.083625000 & 1.260254842 & .445567373 & -2.137224415 & -.030025585 & -2.432 & 7 & .045 \\
\hline $\begin{array}{l}\text { Pair } \\
2\end{array}$ & $\begin{array}{l}\text { Lidar Data- } \\
1 \mathrm{mY}(\mathrm{mN})- \\
\text { UAV-30M y }\end{array}$ & .893250000 & 1.998567040 & .706600153 & -.777593859 & 2.564093859 & 1.264 & 7 & .247 \\
\hline $\begin{array}{l}\text { Pair } \\
3\end{array}$ & $\begin{array}{l}\text { Lidar Data- } \\
1 \mathrm{mZ} \\
\text { (Heights- } \\
\text { m) - UAV- } \\
30 \mathrm{M} \mathrm{z}\end{array}$ & .000000000 & .917598418 & .324420032 & -.767131475 & .767131475 & .000 & 7 & 1.000 \\
\hline
\end{tabular}

Table 5. Paired sample t-Test of LiDAR DATA $1 \mathrm{~m}$ resolution and DEM generated from UAV images acquired at $50 \mathrm{~m}$ flight height

\begin{tabular}{|c|c|c|c|c|c|c|c|c|c|}
\hline & & \multicolumn{5}{|c|}{ Paired Differences } & \multirow{3}{*}{$\mathrm{T}$} & \multirow{3}{*}{ df } & \multirow{3}{*}{$\begin{array}{r}\text { Sig. } \\
(2- \\
\text { tailed })\end{array}$} \\
\hline & & \multirow{2}{*}{ Mean } & \multirow{2}{*}{$\begin{array}{r}\text { Std. } \\
\text { Deviation }\end{array}$} & \multirow{2}{*}{$\begin{array}{r}\text { Std. Error } \\
\text { Mean }\end{array}$} & \multicolumn{2}{|c|}{$\begin{array}{r}95 \% \text { Confidence Interval of } \\
\text { the Difference }\end{array}$} & & & \\
\hline & & & & & Lower & Upper & & & \\
\hline $\begin{array}{l}\text { Pair } \\
1\end{array}$ & $\begin{array}{l}\text { Lidar Data-1mX } \\
(\mathrm{mE}) \text { - UAV-50M x }\end{array}$ & -.620125000 & 2.825751806 & .999054132 & -2.982512629 & 1.742262629 & -.621 & 7 & .554 \\
\hline $\begin{array}{l}\text { Pair } \\
2\end{array}$ & $\begin{array}{l}\text { Lidar Data-1mY } \\
(\mathrm{mN}) \text { - UAV-50M y }\end{array}$ & -.147750000 & 2.522517209 & .891844512 & -2.256627162 & 1.961127162 & -.166 & 7 & .873 \\
\hline $\begin{array}{l}\text { Pair } \\
3\end{array}$ & $\begin{array}{l}\text { Lidar Data-1mZ } \\
\text { (Heights- m) - UAV- } \\
50 \mathrm{M} \mathrm{z}\end{array}$ & .000125000 & .728798510 & .257669184 & -.609165802 & .609415802 & .000 & 7 & 1.000 \\
\hline
\end{tabular}

Furthermore, the result of the paired sample T-test in Table 3 also revealed that there is no statistically significant difference between the means of the $X$ and $Y$ coordinates extracted from the $1 \mathrm{~m}$ LiDAR DEM and $2 \mathrm{~m}$ LiDAR DEM based on their $\mathrm{p}$-value (which is close to 1) at 95\% confidence interval. Though the difference in means of their Z coordinates is statistically insignificant, the obtained p-value is not close to 1 , which implies that the altimetric coordinates obtained from the $2 \mathrm{~m}$ LiDAR DEM are not as reliable planimetric coordinates. From the $\mathrm{p}$-values presented in Table 4, it can be observed that the $\mathrm{X}$ coordinates have a $\mathrm{p}$-value of 0.045 , which is less than 0.05 . This implies that there is a statistically significant difference between the means of the $X$ coordinates extracted from the $1 \mathrm{~m}$ LiDAR DEM and that of the DEM generated from the UAV acquired images at $30 \mathrm{~m}$ flight height. It was also observed that the means of the $Y$ and $Z$ coordinates extracted from the UAV acquired images at $30 \mathrm{~m}$ flight height is not statistically different from that of the $1 \mathrm{~m}$ LiDAR DEM, though the height is more reliable because it gave a perfect p-value of 1.000. As shown in Table 5 , the $p$-values obtained for each of $X, Y, Z$ coordinates $(0.554,0.873$, and 1.000 respectively) are greater than 0.05 , which implies that there is no statistically significant difference between the means of CP coordinates extracted from the $1 \mathrm{~m}$ LiDAR DEM and the DEM generated from the UAV images acquired at $50 \mathrm{~m}$ flight height at $95 \%$ confidence interval. 
Table 6. Paired sample t-Test of LiDAR DATA $1 \mathrm{~m}$ resolution and DEM generated from UAV images acquired at $70 \mathrm{~m}$ flight height

\begin{tabular}{|c|c|c|c|c|c|c|c|c|c|}
\hline & & \multicolumn{5}{|c|}{ Paired Differences } & \multirow[b]{2}{*}{$\mathrm{t}$} & \multirow[b]{2}{*}{ df } & \multirow[b]{2}{*}{$\begin{array}{r}\text { Sig. } \\
(2- \\
\text { tailed })\end{array}$} \\
\hline & & Mean & $\begin{array}{r}\text { Std. } \\
\text { Deviation }\end{array}$ & $\begin{array}{l}\text { Std. Error } \\
\text { Mean }\end{array}$ & \multicolumn{2}{|c|}{$\begin{array}{r}\text { 95\% Confidence Interval of the } \\
\text { Difference }\end{array}$} & & & \\
\hline $\begin{array}{l}\text { Pair } \\
1\end{array}$ & $\begin{array}{l}\text { Lidar Data-1mX } \\
\text { (mE) - UAV-70M } \\
\text { x }\end{array}$ & .159000000 & .761013234 & .269058809 & -.477222986 & .795222986 & .591 & 7 & .573 \\
\hline $\begin{array}{l}\text { Pair } \\
2\end{array}$ & $\begin{array}{l}\text { Lidar Data-1mY } \\
(\mathrm{mN}) \text { - UAV-70M } \\
\mathrm{y}\end{array}$ & .563500000 & 2.711574450 & .958686341 & -1.703432971 & 2.830432971 & .588 & 7 & .575 \\
\hline $\begin{array}{l}\text { Pair } \\
3\end{array}$ & $\begin{array}{l}\text { Lidar Data-1mZ } \\
\text { (Heights- m) - } \\
\text { UAV-70M z }\end{array}$ & 0.000000000 & .724421543 & .256121693 & -.605631566 & .605631566 & 0.000 & 7 & 1.000 \\
\hline
\end{tabular}

This observation was also valid for the results obtained when the $1 \mathrm{~m}$ LiDAR DEM was compared with the DEM generated from the UAV images acquired at $70 \mathrm{~m}$ flight height at a 95\% confidence interval (See Table 6). The UAV based DEM produced when the UAV was flown at $50 \mathrm{~m}$ flight height also yielded an optimal mix or combination of planimetric and altimetric accuracy in this research, which agrees with the findings of Agüera-Vega, Carvajal-Ramirez, \& Martinez-Carricondo (2017). These results further affirm the findings of the horizontal and vertical accuracies, which affirms that the $2 \mathrm{~m}$ LiDAR DEM is more planimetrically accurate when compared to the UAV based DEM but the UAV based DEMs are more accurate than the $2 \mathrm{~m}$ LiDAR DEM in terms of vertical or altimetric coordinates which implies that UAV based DEM is more reliable than LiDAR data of $2 \mathrm{~m}$ resolution for 3D topographic modeling. Also, while the UAV flight height has a significant effect on the horizontal accuracy (planimetric coordinates) of the produced DEMs, it has no significant influence on the vertical accuracy (altimetric coordinates), which is consistent with the findings of Oniga et al. (2018).

\section{CONCLUSION}

In this work, we have analyzed and compared the accuracy of DEMs generated from LiDAR data of $2 \mathrm{~m}$ resolution, UAV images acquired at $30 \mathrm{~m}, 50 \mathrm{~m}$, and $70 \mathrm{~m}$ flight heights using LiDAR data of $1 \mathrm{~m}$ resolution as a reference benchmark. The UAV acquired images were processed for DEM generation using Agisoft Photoscan digital photogrammetric software. From the findings of the research, the following conclusions were drawn:

1. The planimetric coordinates extracted from the $2 \mathrm{~m}$ resolution LiDAR data are in better agreement with the planimetric coordinates extracted from the $1 \mathrm{~m}$ resolution LiDAR data.

2. The altimetric coordinates extracted from the UAV based DEM (irrespective of the flight height of the UAV during image acquisition) agrees better with the altimetric coordinates of the $1 \mathrm{~m}$ resolution LiDAR data when compared with the $2 \mathrm{~m}$ resolution LiDAR data, which shows that the altimetric accuracy obtainable from UAV based DEM is better than the altimetric accuracy obtainable from LiDAR technology at $2 \mathrm{~m}$ resolution (This is valid as long as the flight height of the UAV does not exceed $70 \mathrm{~m}$ as experimented in this research).

3. The difference in the UAV's flight height does not have any significant effect on the obtainable accuracy of the altimetric coordinates. 
4. The most reliable accuracy of both planimetric and altimetric coordinates was obtained from the DEM produced from the UAV images acquired at $50 \mathrm{~m}$ flight altitude. It conveniently competes with LiDAR technology even at $1 \mathrm{~m}$ resolution and can be a robust alternative to the very expensive LiDAR technology in topographic modeling, especially in inaccessible areas.

\section{ACKNOWLEDGMENTS}

The visiting academic scholarship granted to the first author by the Faculty of Environment and Technology, University of the West of England, Bristol, UK is gratefully acknowledged. This research was conducted in the course of the visit.

\section{REFERENCES}

Agüera-Vega, F., Carvajal-Ramirez, F., \& Martinez-Carricondo, P. (2017). Accuracy of digital surface models and orthophotos derived from unmanned aerial vehicle photogrammetry. Journal of Surveying Engineering, 143(2), 4016025. [Crossref]

Ajayi, O. G., Salubi, A. A., Angbas, A. F., \& Odigure, M. G. (2017). Generation of accurate digital elevation models from UAV acquired low percentage overlapping images. International Journal of Remote Sensing, 38(8-10), 3113-3134. [Crossref]

Alonzo, M., Bookhagen, B., \& Roberts, D. A. (2014). Urban tree species mapping using hyperspectral and lidar data fusion. Remote Sensing of Environment, 148, 70-83. [Crossref]

Anderson, K., \& Gaston, K. J. (2013). Lightweight unmanned aerial vehicles will revolutionize spatial ecology. Frontiers in Ecology and the Environment, 11(3), 138-146. [Crossref]

Antonarakis, A. S., Richards, K. S., \& Brasington, J. (2008). Object-based land cover classification using airborne LiDAR. Remote Sensing of Environment, 112(6), 2988-2998. [Crossref]

Ardiansyah, P. O. D., \& Yokoyama, R. (2002). DEM generation method from contour lines based on the steepest slope segment chain and a monotone interpolation function. ISPRS Journal of Photogrammetry and Remote Sensing, 57(1-2), 86-101. [Crossref]

Arun, P. V. (2013). A comparative analysis of different DEM interpolation methods. The Egyptian Journal of Remote Sensing and Space Science, 16(2), 133-139. [Crossref]

Bhardwaj, A., Sam, L., Martin-Torres, F. J., \& Kumar, R. (2016). UAVs as remote sensing platform in glaciology: Present applications and future prospects. Remote Sensing of Environment, 175, 196-204. [Crossref]

Brunner, F. K. (1984). Modelling of atmospheric effects on terrestrial geodetic measurements. In Geodetic Refraction (pp. 143-162). Springer. [Crossref]

Candiago, S., Remondino, F., De Giglio, M., Dubbini, M., \& Gattelli, M. (2015). Evaluating multispectral images and vegetation indices for precision farming applications from UAV images. Remote Sensing, 7(4), 40264047. [Crossref]

Chu, T., \& Lindenschmidt, K.-E. (2017). Comparison and validation of digital elevation models derived from InSAR for a flat inland delta in the high latitudes of Northern Canada. Canadian Journal of Remote Sensing, 43(2), 109-123. [Crossref]

Demirkesen, A. C., Evrendilek, F., Berberoglu, S., \& Kilic, S. (2007). Coastal flood risk analysis using Landsat-7 ETM+ imagery and SRTM DEM: A case study of Izmir, Turkey. Environmental Monitoring and Assessment, 131(1), 293-300. [Crossref]

Doyle, T. B., \& Woodroffe, C. D. (2018). The application of LiDAR to investigate foredune morphology and vegetation. Geomorphology, 303, 106-121. [Crossref]

Everaerts, J. (2008). The use of unmanned aerial vehicles (UAVs) for remote sensing and mapping. The International Archives of the Photogrammetry, Remote Sensing and Spatial Information Sciences, 37(2008), 1187-1192. [Crossref]

Gelautz, M., Paillou, P., Chen, C. W., \& Zebker, H. A. (2003). Radar stereo-and interferometry-derived digital elevation models: comparison and combination using Radarsat and ERS-2 imagery. International Journal of Remote Sensing, 24(24), 5243-5264. [Crossref] 
Gonçalves, J. A., \& Henriques, R. (2015). UAV photogrammetry for topographic monitoring of coastal areas. ISPRS Journal of Photogrammetry and Remote Sensing, 104, 101-111. [Crossref]

Gruber, A., Wessel, B., Huber, M., \& Roth, A. (2012). Operational TanDEM-X DEM calibration and first validation results. ISPRS Journal of Photogrammetry and Remote Sensing, 73, 39-49. [Crossref]

Hanssen, R. F. (2001). Radar interferometry: data interpretation and error analysis (Vol. 2). Springer Science \& Business Media.

Hardin, P. J., \& Jensen, R. R. (2011). Small-scale unmanned aerial vehicles in environmental remote sensing: Challenges and opportunities. GIScience \& Remote Sensing, 48(1), 99-111. [Crossref]

Hartley, R., \& Zisserman, A. (2003). Multiple view geometry in computer vision. Cambridge university press.

Hoja, D., Reinartz, P., \& Schroeder, M. (2007). Comparison of DEM generation and combination methods using high resolution optical stereo imagery and interferometric SAR data. Revue Française de Photogrammétrie et de Télédétection, 2006(4), 89-94.

https://digimap.edina.ac.uk/webhelp/digimapsupport/description/lidar_overview.htm

https://digimap.edina.ac.uk/webhelp/lidar/data_information/lidar_dtm.htm

https://www.derelictplaces.co.uk/main/military-sites/31371-st-thomas-head-weston-supermare.html\#.Wp6Y6GrFKM8

Huang, C. M., Guo, J. K., Zhao, Z., Xiao, Z., Qiu, C. P., Pang, L., \& Wang, Z. Y. (2004). DEM generation from stereo SAR images based on polynomial rectification and height displacement. IGARSS 2004. 2004 IEEE International Geoscience and Remote Sensing Symposium, 6, 4227-4230. [Crossref]

James, M. R., Robson, S., d'Oleire-Oltmanns, S., \& Niethammer, U. (2017). Optimising UAV topographic surveys processed with structure-from-motion: Ground control quality, quantity and bundle adjustment. Geomorphology, 280, 51-66. [Crossref]

Knoth, C., Klein, B., Prinz, T., \& Kleinebecker, T. (2013). Unmanned aerial vehicles as innovative remote sensing platforms for high-resolution infrared imagery to support restoration monitoring in cut-over bogs. Applied Vegetation Science, 16(3), 509-517. [Crossref]

Li, X., Fu, W., Shen, H., Huang, C., \& Zhang, L. (2017). Monitoring snow cover variability (2000--2014) in the Hengduan Mountains based on cloud-removed MODIS products with an adaptive spatio-temporal weighted method. Journal of Hydrology, 551, 314-327. [Crossref]

Li, X., Shen, H., Feng, R., Li, J., \& Zhang, L. (2017). DEM generation from contours and a low-resolution DEM. ISPRS Journal of Photogrammetry and Remote Sensing, 134, 135-147. [Crossref]

Linchant, J., Lisein, J., Semeki, J., Lejeune, P., \& Vermeulen, C. (2015). Are unmanned aircraft systems (UAS s) the future of wildlife monitoring? A review of accomplishments and challenges. Mammal Review, 45(4), 239-252. [Crossref]

Long, N., Millescamps, B., Guillot, B., Pouget, F., \& Bertin, X. (2016). Monitoring the topography of a dynamic tidal inlet using UAV imagery. Remote Sensing, 8(5), 387. [Crossref]

Moussa, A., \& El-Sheimy, N. (2010). Automatic classification and 3D modeling of LiDAR data. Proceedings of the ISPRS Commission III Symposium-PCV.

Ogundare, F. O., \& Adekoya, O. I. (2015). Gross alpha and beta radioactivity in surface soil and drinkable water around a steel processing facility. Journal of Radiation Research and Applied Sciences, 8(3), 411417. [Crossref]

Olivera, F., Furnans, J., Maidment, D., Djokic, D., \& Ye, Z. (2002). Drainage systems, ArcHydro: GIS for water resource. ESRI Press, Redlands, 203.

Olsen, M. J., Young, A. P., \& Ashford, S. A. (2012). TopCAT-Topographical Compartment Analysis Tool to analyze seacliff and beach change in GIS. Computers \& Geosciences, 45, 284-292. [Crossref]

Oniga, V.-E., Breaban, A.-I., \& Statescu, F. (2018). Determining the optimum number of ground control points for obtaining high precision results based on UAS images. Multidisciplinary Digital Publishing Institute Proceedings, 2(7), 352. [Crossref]

Peralvo, M., \& Maidment, D. (2004). Influence of DEM interpolation methods in drainage analysis. Gis Hydro, 4.

Radtke, P. J., Boland, H. T., \& Scaglia, G. (2010). An evaluation of overhead laser scanning to estimate herbage removals in pasture quadrats. Agricultural and Forest Meteorology, 150(12), 1523-1528. [Crossref] 
Reddy, A. D., Hawbaker, T. J., Wurster, F., Zhu, Z., Ward, S., Newcomb, D., \& Murray, R. (2015). Quantifying soil carbon loss and uncertainty from a peatland wildfire using multi-temporal LiDAR. Remote Sensing of Environment, 170, 306-316. [Crossref]

Ricchetti, E. (2001). Visible? infrared and radar imagery fusion for geological application: A new approach using DEM and sun-illumination model. International Journal of Remote Sensing, 22(11), 2219-2230. [Crossref]

Rishikeshan, C. A., Katiyar, S. K., \& Mahesh, V. N. V. (2014). Detailed evaluation of DEM interpolation methods in GIS using DGPS data. 2014 International Conference on Computational Intelligence and Communication Networks, 666-671. [Crossref]

Rott, H. (2009). Advances in interferometric synthetic aperture radar (InSAR) in earth system science. Progress in Physical Geography, 33(6), 769-791. [Crossref]

Rüeger, J. M. (1990). On the use of inexpensive reflectors in EDM. Australian Surveyor, 35(3), $238-247$. [Crossref]

Shahbazi, M., Théau, J., \& Ménard, P. (2014). Recent applications of unmanned aerial imagery in natural resource management. GIScience \& Remote Sensing, 51(4), 339-365. [Crossref]

Simpson, J. E., Wooster, M. J., Smith, T. E. L., Trivedi, M., Vernimmen, R. R. E., Dedi, R., ... Dinata, Y. (2016). Tropical peatland burn depth and combustion heterogeneity assessed using UAV photogrammetry and airborne LiDAR. Remote Sensing, 8(12), 1000. [Crossref]

Tijskens, E., Ramon, H., \& De Baerdemaeker, J. (2003). Discrete element modelling for process simulation in agriculture. Journal of Sound and Vibration, 266(3), 493-514. [Crossref]

Torge, W., \& Müller, J. (2012). Geodesy. Walter de Gruyter.

Tsai, F., Hwang, J.-H., Chen, L.-C., \& Lin, T.-H. (2010). Post-disaster assessment of landslides in southern Taiwan after 2009 Typhoon Morakot using remote sensing and spatial analysis. Natural Hazards and Earth System Sciences, 10(10), 2179. [Crossref]

Turner, D., Lucieer, A., Malenovský, Z., King, D. H., \& Robinson, S. A. (2014). Spatial co-registration of ultrahigh resolution visible, multispectral and thermal images acquired with a micro-UAV over Antarctic moss beds. Remote Sensing, 6(5), 4003-4024. [Crossref]

Ussisoo, I. (1969). Correction problems in electronic distance measurements. Tellus, 21(4), 549-567. [Crossref]

Ussyshkin, R. V., Theriault, L., Sitar, M., \& Kou, T. (2011). Advantages of airborne lidar technology in power line asset management. 2011 International Workshop on Multi-Platform/Multi-Sensor Remote Sensing and Mapping, 1-5. [Crossref]

Wallace, L., Lucieer, A., Watson, C., \& Turner, D. (2012). Development of a UAV-LiDAR system with application to forest inventory. Remote Sensing, 4(6), 1519-1543. [Crossref]

Westoby, M. J., Brasington, J., Glasser, N. F., Hambrey, M. J., \& Reynolds, J. M. (2012). "Structure-fromMotion"photogrammetry: A low-cost, effective tool for geoscience applications. Geomorphology, 179, 300-314.

Whitehead, K., Hugenholtz, C. H., Myshak, S., Brown, O., LeClair, A., Tamminga, A., ... Eaton, B. (2014). Remote sensing of the environment with small unmanned aircraft systems (UASs), part 2: Scientific and commercial applications. Journal of Unmanned Vehicle Systems, 2(3), 86-102.

Wieser, H.-P., Cisternas, E., Wahl, N., Ulrich, S., Stadler, A., Mescher, H., ... others. (2017). Development of the open-source dose calculation and optimization toolkit matRad. Medical Physics, 44(6), 2556-2568. [Crossref]

Xu, Z., Yang, F., Huang, Y., Wang, Z., \& Liu, Y. (2008). Lidar applications in the electrical power industry. Int. Arch. Photogramm. Remote Sens. Spat. Inf. Sci, 36, 137-140.

Yan, W. Y., Shaker, A., \& El-Ashmawy, N. (2015). Urban land cover classification using airborne LiDAR data: A review. Remote Sensing of Environment, 158, 295-310. [Crossref]

Yang, L., Meng, X., \& Zhang, X. (2011). SRTM DEM and its application advances. International Journal of Remote Sensing, 32(14), 3875-3896. [Crossref]

You, A., Wang, X., Han, X., \& Tang, D. (2013). Applications of LiDAR in patrolling electric-power lines. 2013 The International Conference on Technological Advances in Electrical, Electronics and Computer Engineering (TAEECE), 110-114. [Crossref] 
Yuan, X. (2003). Introduce to the Spaceborne Synthetic Aperture Radar. National Defense Industry Press, Beijing.

Yue, L., Shen, H., Yuan, Q., \& Zhang, L. (2015). Fusion of multi-scale DEMs using a regularized super-resolution method. International Journal of Geographical Information Science, 29(12), 2095-2120. [Crossref] 